\title{
El café de Fornos (1870-1909) de Madrid, epicentro social y cultural en la calle de Alcalá
}

\author{
The café de Fornos (1870-1909) of Madrid, social \\ and cultural epicenter in the Street of Alcalá
}

\author{
Mónica VÁzQUEZ ASTORGA
}

Profesora Titular. Departanto de Historia del Arte. Universidad de Zaragoza mvazquez@unizar.es

Recibido: 23/05/2018

Aceptado: $12 / 09 / 2018$

\section{Resumen}

Este texto se centra en el estudio del café de Fornos (calle de Alcalá esquina con la de la Virgen de los Peligros) de Madrid. Fue inaugurado el 20 de julio de 1870 por los hermanos Manuel y Carlos Fornos y su nombre estuvo unido a la vida madrileña hasta su clausura en agosto de 1909. En su interior atesoraba artísticas pinturas y destacaba por su elegante decoración y lujo (no superados posteriormente por ningún otro café). Fue sitio de reunión de políticos, artistas y literatos y epicentro de la bohemia histórica, así como tuvo un notable impacto en su entorno urbano.

Palabras clave

Cafés históricos, Madrid, café de Fornos, pintura decorativa, lugares de reunión y de tertulias, espacio urbano.

\section{Keywords}

Historical cafés, Madrid, café de Fornos, decorative painting, meeting and debate venues, urban space. 


\begin{abstract}
This text focuses on the study of café de Fornos (calle de Alcalá esquina con la de la Virgen de los Peligros) of Madrid. It was inaugurated on July 20, 1870 by the brothers Manuel and Carlos Fornos and its name was linked to the life of Madrid until its closure in August 1909. Inside it hoarded artistic paintings and stood out for its elegant decoration and luxury. It was a meeting place for politicians, artists and writers and the epicenter of historical bohemia, as well as had a notable impact on their urban space.
\end{abstract}

Referencia normalizada: VÁZQUEZ ASTORGA, MÓNICA (2018): “El Café Fornos (18701909) de Madrid, epicentro social y cultural en la calle de Alcalá". Arte y Ciudad. Revista de Investigación, oํ 14 (octubre), págs. 7-32. Madrid. Grupo de Investigación Arte, Arquitectura y Comunicación en la Ciudad Contemporánea, Universidad Complutense de Madrid.

Sumario: 1. Introducción. 2. El Fornos, templo del arte. 3. El Madrid que se va: declive y cierre del Fornos. 4. El recuerdo del Fornos. 5. Bibliografía.

\footnotetext{
** Este trabajo se ha realizado en el marco del Proyecto Museos y distritos culturales: Arte e instituciones en zonas de renovación arquitectónico-urbanística, financiado por la Secretaria de Estado de I+D+i del Ministerio de Economía y Competitividad (código HAR2015-66288-C4-01-P) (MINECO/FEDER) y con el Dr. Jesús Pedro Lorente como investigador principal.
}

\title{
1. Introducción.
}

En estas páginas nos centramos en el estudio del café de Fornos (calle de Alcalá, 1870-1909) porque fue uno de los establecimientos más notables en su género que existieron en Madrid en esas fechas. Su nombre estuvo unido a la vida madrileña desde los primeros años de la Revolución de Septiembre, cuando ya funcionaba su antecesor el Europeo (calle de Sevilla), hasta su clausura definitiva en agosto de 1909. En su interior atesoraba artísticas pinturas y destacaba por su elegante decoración y lujo (no superados posteriormente por ningún otro café), que fundamentan que fuera definido en la época "como un templo en el que se rendía tributo al arte" (Gil Blas, 1870: 3), y que estuviera considerado como uno de los mejores e, incluso, a la altura de los más acreditados a nivel europeo.

Como bien señala $M^{a}$. Victoria López-Cordón, la segunda mitad del siglo XVIII se caracterizó por la apertura de nuevos centros públicos de sociabili- 
dad (entre ellos, el café) que, a imitación de lo que ocurría en otras ciudades europeas, aspiraban a convertirse en lugares de encuentro en los que, con el pretexto de tomar una determinada consumición, se participaba en distintos juegos y, también, se hablaba de asuntos del día (López-Cordón, 2014: 345).

Además, y como constata Juan Francisco Fuentes, el café constituyó el núcleo de un nuevo espacio burgués y mesocrático que vino a romper con el doble carácter socialmente hermético y promiscuo de la sociedad estamental. Como parcela de libertad que anticipó y preparó el triunfo de la burguesía, su papel fue particularmente decisivo en la creación de una moderna opinión pública, entendida como libre intercambio de ideas (Fuentes, 2001: 209).

El Fornos fue fundado en julio de 1870 por los hermanos Manuel y Carlos Fornos, que se caracterizaron por su talante liberal y por su actividad emprendedora en el sector industrial. De ahí que fuera refugio y sitio de reunión de quienes profesaban las ideas y aspiraciones de los dueños ${ }^{1}$. Como después desarrollaremos, fue un notorio escenario de tertulias, debates y banquetes.

Estuvo emplazado en uno de los puntos más estratégicos de Madrid como es la calle de Alcalá, esquina a la de la Virgen de los Peligros (distrito Centro), por tanto, en uno de los lugares de más animación y vida de la ciudad. Se hallaba frente al acreditado café Suizo (que fue inaugurado el 3 de junio de 1845 por la sociedad Matossi, Fanconi y compañía) ${ }^{2}$ y al lujoso Trianon Palace (calle de Alcalá, núm. 20, cuyo estreno tuvo lugar el 15 de abril de 1911) ${ }^{3}$ y a unos pasos del teatro Apolo ${ }^{4}$ (calle de Alcalá, núm. 49) 5 .

\footnotetext{
${ }^{1}$ Sobre este tema, véase (Sánchez, 2017: 405-426).

${ }^{2}$ El Suizo se instaló en una casa de reciente construcción ubicada en la calle de Alcalá, núm. 36, esquina con la Ancha de Peligros -luego calle de Sevilla, núm. 16- (El Heraldo, 1845: 4).

${ }^{3}$ El Trianon Palace combinaba las sesiones cinematográficas con los espectáculos llamados de varietés y las representaciones teatrales (A.V.M., 1910) y (El Imparcial, 1911: 2). A finales del año 1919 la finca que ocupaba el Trianon fue demolida y en su solar se levantó el teatro Alkázar, que fue inaugurado a finales de enero de 1925 (El Imparcial, 1925: 3).

${ }^{4}$ Este teatro fue inaugurado en la noche del 23 de noviembre de 1873. El techo de su salón y del foyer fue pintado por Francisco Sans Cabot (director en esos momentos del Museo del Prado) (Diario Oficial de Avisos de Madrid, 1873: 4) y (La Ilustración Española y Americana, 1873: 723 y 725).

${ }^{5} \mathrm{Al}$ café de Fornos acudían los espectadores de la cuarta del Apolo, una vez terminada la función. El Apolo era el único teatro que celebraba cuatro funciones diarias y la última comenzaba a las doce de la noche (Martín, 2008: 136).
} 
La calle de Alcalá era, en esos momentos, "la arteria más importante de la villa y de la corte" (La Libertad, 1921: 4), y concentraba un considerable número de cafés como el de Cervantes (calle de Alcalá, núm. 59, esquina con la calle del Barquillo, núm. 1; ubicado en la planta baja del antiguo palacio del Marqués de Casa-Irujo y abierto el 31 de marzo de 1839) (Diario de Madrid, 1839: 2); Imperial (calle de Alcalá, núm. 1, esquina con la Puerta del Sol y Carrera de San Jerónimo, inaugurado el 1 de septiembre de 1864) (La España, 1864: 4); y de Madrid (calle de Alcalá y Carrera de San Jerónimo ${ }^{6}$, instalado en diciembre de 1866). Este último era amplio (ocupaba las plantas baja y entresuelo del inmueble) y elegante, y fue uno de los primeros establecimientos de este tipo en acoger en su interior un programa pictórico formulado conforme a un criterio de conjunto. Sus paredes fueron decoradas con obras de renombrados pintores y con esculturas de inspiración clásica (La Esperanza, 1866: 4-5). Entre los artistas y escenógrafos que trabajaron en 1866 en este café se encontraban José Vallejo y Galeazo, Vicente Palmaroli y González, Augusto Ferri, Antonio Bravo, Francisco Plá y Vila, Luis Álvarez, Montalvo y García y Francisco Aznar y García (Vázquez, 2017: 367-369).

No obstante, entre todos los citados, destacaba el Suizo, dado que era elogiado por la sociedad como "tribuna" política y cuartel general de escritores y artistas (La Ilustración Artística, 1885: 3). De este modo, fue el espacio escogido para la adjudicación de premios por parte del Jurado a los autores que participaron en la Exposición Nacional de Bellas Artes de 1871 (La Ilustración Española y Americana, 1871: 529). También es interesante señalar que el Círculo de Bellas Artes surgió en 1879 en una de sus tertulias, de la que formaban parte un grupo de literatos (Ulpiano Segarra, Eduardo Lustonó, Enrique Esteban y Antonio Pérez Rubio, entro otros) y pintores y escultores (como Plácido Francés, Arturo Mélida, Aureliano de Beruete y Carlos de Haes), con la idea de formar una institución cultural en la que pudiesen exponer y vender sus obras sin contar con los marchantes 7 .

Asimismo, en la calle de Alcalá tuvieron su residencia famosos artistas de la época como el pintor burgalés Marceliano Santa María (1866-1952), en el núm. 50 de la misma (El Imparcial, 1905: 3).

\footnotetext{
${ }^{6}$ Este café fue unido, en el verano de 1867, al del Iris (calle de Alcalá y Carrera de San Jerónimo) con el fin de convertirlo en un único y espacioso local denominado de Madrid (Diario Oficial de Avisos de Madrid, 1867: 4).

${ }^{7}$ El reglamento de esta asociación quedó aprobado el 29 de diciembre de 1879 y así constituida definitivamente en la calle del Barquillo, núm. 5 (La Época, 1895: 2).
} 
Igualmente, en sus inmediaciones se localizaban otros espacios de sociabilidad, en particular asociativa, como el Ateneo Científico, Literario y Artístico (calle de la Montera, núm. 22) ${ }^{8}$ o el Casino (calle del Príncipe, núm. 14)9 ${ }^{9}$ que impusieron progresivamente su marca en esta área urbana, dinamizándola e impulsándola culturalmente. Además, se hallaban próximas varias instituciones artísticas como la Real Academia de Bellas Artes de San Fernando (calle de Alcalá, núm. 13), el Círculo de Bellas Artes (plaza de las Cortes, núm. 4) o el salón de exposiciones de las Galerías Nancy (Carrera de San Jerónimo, núm. 40); así como el Museo Nacional (instalado en 1838 en el suprimido convento de la Trinidad Calzada ${ }^{10}$, de ahí que fuera denominado Museo Nacional de la Trinidad, que ocupaba una enorme manzana entre las calles de Atocha, Calatrava y Concepción Jerónima hasta la que hoy es conocida como plaza de Tirso de Molina), que revitalizaron esta zona convirtiéndola en un "barrio artístico"11.

\footnotetext{
${ }^{8}$ Desde su origen en 1835, el Ateneo fue considerado indistintamente como Academia científica, Instituto de enseñanza y Círculo literario (Villacorta, 1985: 2). El 31 de enero de 1884 se inauguró el edificio de su nueva sede en la calle del Prado (El Imparcial, 1884: 2).

${ }^{9}$ El origen del Casino se remonta al año 1836 y, en 1840, se estableció en el número 14 de la calle del Príncipe (Zozaya, 2008: 139-140 y 700). El Casino se mudó de esta sede a la Carrera de San Jerónimo y, en 1880, se trasladó a la planta principal del edificio que ocupaba el café del Suizo, que entonces alojaba también al Casino de la Gran Peña (en el entresuelo). En su inmueble estuvieron además instalados hoteles y redacciones de periódicos, así como la sociedad aristocrática Veloz-Club (El Imparcial, 1919: 4) y (Castrovido, 1926: 590). En enero de 1891, el Casino se trasladó al edificio de nueva planta de la sociedad de seguros La Equitativa (calle de Alcalá, núm. 14, esquina con la calle de Sevilla, núms. 3 y 5), casi enfrente del Suizo, donde estuvo hasta 1910 en que inauguró la casa de su propiedad en la calle de Alcalá, núm. 15 (La Ilustración española y americana, 1891: 107, 110 y 112).

${ }^{10}$ La apertura del Museo de la Trinidad se produjo el 24 de julio de 1838 (El Eco del Comercio, 1838: 4). Los fondos de este museo se fundieron con los del Museo Nacional de Pintura y Escultura del Prado (abierto al público en 1819) mediante un decreto del 25 de noviembre de 1870, promulgado por la Regencia, después sustituido por otro del 22 de marzo de 1872 ya emitido por el rey Amadeo de Saboya. El edificio del antiguo convento fue derribado en 1897 (Antigüedad del Castillo-Olivares, 1998: 395).

${ }^{11}$ El profesor Jesús-Pedro Lorente (2009: 15) define un "barrio artístico" como aquel en el que hay una alta concentración de presencias artísticas, entre las cuales habría que distinguir tres factores: la afluencia de artistas -en la calle, en talleres o residencias, en cafés y locales de ocio-; la abundancia de arte en el espacio público -murales, esculturas y monumentos, arquitecturas de mérito, mobiliario urbano, etc.-; y la profusión en dicho distrito de establecimientos artísticos -academias o escuelas de arte, museos, galerías de marchantes o fundaciones-. Puede hablarse de barrio artístico aunque solo aparezca uno de estos tres factores, con tal de que se dé en altas proporciones.
} 
Para abordar el tema objeto de estudio realizamos, en primer lugar, un recorrido histórico por el período más floreciente de este café que comprende desde su apertura en julio de 1870 hasta finales de la década de los ochenta de esa centuria. En estos momentos fue elegido como uno de los ámbitos preferentes de encuentro social y fue reconocido como "templo del arte" por su decoración debida a célebres firmas académicas; en segundo lugar, nos centramos en los años en los que comenzó su declive, que condujo a su cierre definitivo en agosto de 1909; y, por último, aludimos a los varios destinos que tuvo el local del antiguo Fornos hasta la demolición de su inmueble en 1933.

\section{El Fornos, templo del arte.}

A mediados del siglo XVIII y a imitación de los existentes en Londres, París o Viena, se abrieron numerosos cafés en las principales ciudades españolas. Fue en la década de 1760 cuando, como indica Bonet Correa, surgieron estos nuevos espacios públicos de sociabilidad (Bonet, 2012: 202), y poco tiempo después ya se publicitaban en la prensa madrileña los cafés de las Cuatro Naciones en la calle de Fuencarral, núm. 3 (Diario curioso, 1787: 354), o de Levante en la calle de Alcalá, núm. 15 (frente a la desaparecida iglesia del Buen Suceso) (Diario de Madrid, 1788: 807). Estos establecimientos fueron incrementándose y mejorando sus instalaciones y servicios a partir de mediados del siglo XIX. La mayoría de ellos se hallaban situados en el distrito Centro (en la Puerta del Sol y en sus calles afluentes -Carrera de San Jerónimo, Montera o Alcalá-, que eran las principales y más transitadas de la ciudad), donde también se concentraba la actividad cultural y comercial. De hecho, la calle de Alcalá era pródiga en cafés y, en su primer tramo -de Sol a Peligros- la nota característica era la del Colonial, Madrid o Fornos, y tras la calle de Sevilla, estaba el Suizo, y cada uno de ellos tenía un acusado perfil.

La apertura del café de Fornos se produjo poco tiempo después de la Revolución de septiembre de 1868, que puso fin a la monarquía isabelina y fue, como advierte María Victoria López-Cordón, una brusca sacudida en la historia de nuestro siglo XIX (López-Cordón, 1976: 1). “La Gloriosa” se vio seguida por el paréntesis liberal del Sexenio Democrático, y éste, a su vez, por los años de la Restauración y de la regencia de María Cristina, durante el último tercio del siglo XIX y los primeros años del siglo XX, que se corresponden con el período de mayor desarrollo de los cafés en nuestro país, es decir, con su Edad de Oro (Bonet, 2012: 38). 
El Fornos (sito en la calle de Alcalá esquina con la de la Virgen de los Peligros, casi medianero con el edificio de la Aduana) fue inaugurado el 20 de julio de 1870 por los hermanos Manuel y Carlos Fornos, y un día después se abrió al público (Diario Oficial de Avisos de Madrid, 1870: 4). Su inmueble fue proyectado por el arquitecto cántabro Jerónimo de la Gándara y se convirtió en uno de los más distinguidos y monumentales de la calle de Alcalá (Cabello, 1933: 15) (Fig. 1). Su nombre va unido al del desaparecido convento de Nuestra Señora de la Piedad (conocido como de las Vallecas) ${ }^{12}$, dado que sobre sus solares se levantaron la casa de este café y del restaurant de los Cisnes. Antes de su construcción, este terreno albergó un barracón improvisado en el que se celebraron exposiciones de pintura como la que tuvo lugar en 1864, y en la que se exhibieron dos cuadros del artista valenciano Salvador Martínez Cubells (titulados El baile y Visita del novio), entre otras obras (La Ilustración Moderna, 1892: 108).

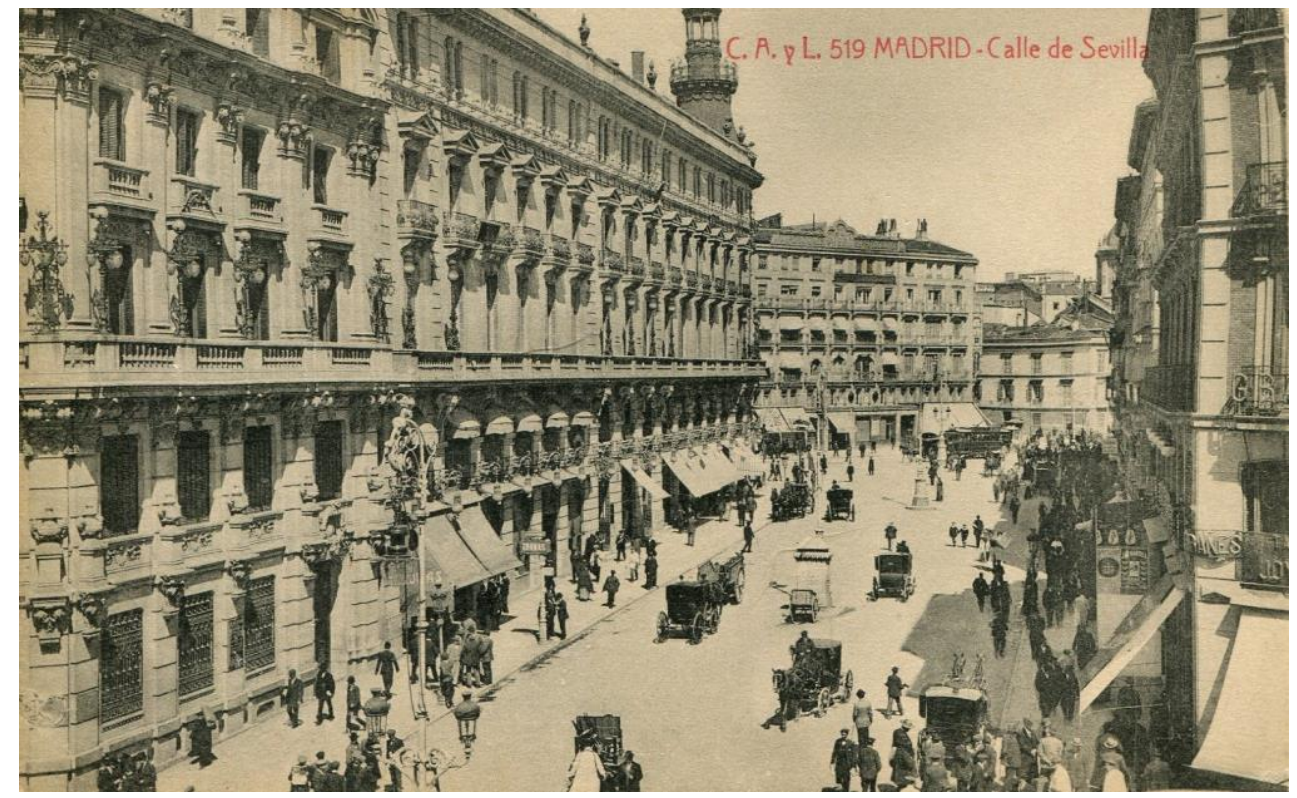

Figura 1. Vista parcial de la calle de Sevilla y al fondo se aprecia la calle de Alcalá y el edificio del café de Fornos (con toldo), angular con la calle de los Peligros, hacia 1920. Fuente: colección particular.

\footnotetext{
${ }^{12}$ La comunidad de las religiosas bernardas de Nuestra Señora de la Piedra de Madrid fue expulsada de su convento por virtud de la ley de 29 de julio de 1837 (El movimiento católico, 1897: 1).
} 
Este café fue establecido por los hijos de Pepe Fornos, dueños hasta ese momento del café Europeo (calle de Sevilla ${ }^{13}$, cuyo local fue ocupado luego por el café Inglés). Era muy amplio y constaba de plantas baja -para café- y entresuelo -destinada a restaurant y a cuartos reservados para tertulias-. Contaba también con servicio de repostería. La prensa de la época lo elogió con estas palabras el día de su inauguración:

Es uno de los primeros en su clase y contiene preciosidades como ningún otro, entre ellas cuatro medallones al fresco pintados por Vallejo, que representan alegorías del té, del café, del chocolate y de los vinos. Hay además un espejo de tamaño colosal y numerosos divanes que son de chagrén -que ha costado a tres duros el pie- (Diario Oficial de Avisos de Madrid, 1870: 4).

Por tanto, fue instalado con todo lujo, con pinturas y tapices de buen gusto, con un elegante mobiliario (fabricado por el artista Guerrero) compuesto de sillas de madera (de la empresa Thonet), mesas de diversas formas y cómodos divanes de tafilete en azul -en lugar de rojo, como era lo habitual- que invitaban a la charla relajada, con grandes espejos, con figuras de bronce que sostenían las lámparas de gas, con un reloj de dos esferas y con un refinado servicio de cristalería.

\footnotetext{
${ }^{13}$ La familia Fornos estuvo primero al frente del café de las Cuatro Naciones (en los años cincuenta, que ocupaba un local reducido pero decente en la calle de Sevilla), que fue escenario de los sucesos políticos del momento y, en concreto, de uno de los momentos cruciales de la revolución de 1854 como fue la insurrección popular que se inició por los progresistas y demócratas el 14 de julio en Barcelona y el 17 de julio en Madrid. Así, en la prensa madrileña de la época se relataba esta noticia: "Manuel Antonio Fornos, dueño del café de las Cuatro Naciones, fue uno de los valientes patriotas que sellaron con su sangre su amor a la libertad. El 18 de julio por la tarde se construyeron las barricadas del Suizo y de la Carrera de San Gerónimo con bastante peligro. Se asomó a los balcones de su casa, café de las Cuatro Naciones, con don Sebastián Pérez Benedicto. Del acierto de sus tiros y de los de su compañero Sebastián resultaron muertos o heridos varios civiles" (El Clamor público, 1854: 1).

A partir del 8 de marzo de 1861, esta familia pasó a gestionar el café Europeo (situado en la acera de enfrente del café antes citado, en la misma calle), que era uno de los más elegantes y mejor servidos de Madrid (Diario oficial de avisos de Madrid, 1852: 2) y (El Contemporáneo, 1861: 4).

Como constata Antonio Velasco, cuando Pepe Fornos falleció, sus cuatro hijos (y sobre todo el mayor, Manuel Fornos) quisieron continuar con el negocio del padre, pero ampliándolo y trasladándolo a la próxima esquina de la calle de Alcalá con la de Peligros, a un nuevo edificio, dando al nuevo establecimiento el nombre de Fornos (Velasco, 1945: 14).
} 
El techo de su salón principal fue pintado con cuatro magníficos frescos por el malagueño José Vallejo y Galeazo ${ }^{14}$, que representaban alegóricamente el té, el café, el chocolate y los vinos ${ }^{15}$. El que plasmaba el té mostraba una composición en la que un cielo con nubes servía de escenario y en el que se disponían dos figuras femeninas sedentes (en el centro) que estaban degustando plácidamente esta preciada bebida (Fig. 2). Una de ellas estaba revestida con ropaje, que dejaba parte de su cuerpo descubierto, y sosteniendo con su mano derecha una taza, en la que un putti le vierte té. Por su parte, la otra portaba indumentaria de inspiración japonesa y un cuenco sin asa en su mano izquierda (cuyo contenido está ingiriendo), en alusión a la procedencia oriental de esta infusión. Una refinada decoración estilo Luis XV completaba los salones, y en la que sobre fondo blanco con filetes, florones y molduras de oro lucían caprichosas grecas, cuadros de paisaje, pájaros y flores vistosas, que fue realizada por los famosos escenógrafos italianos Augusto Ferri y Giorgio Busato (Bécquer, 1870: 8-9 y 15-16) ${ }^{16}$.

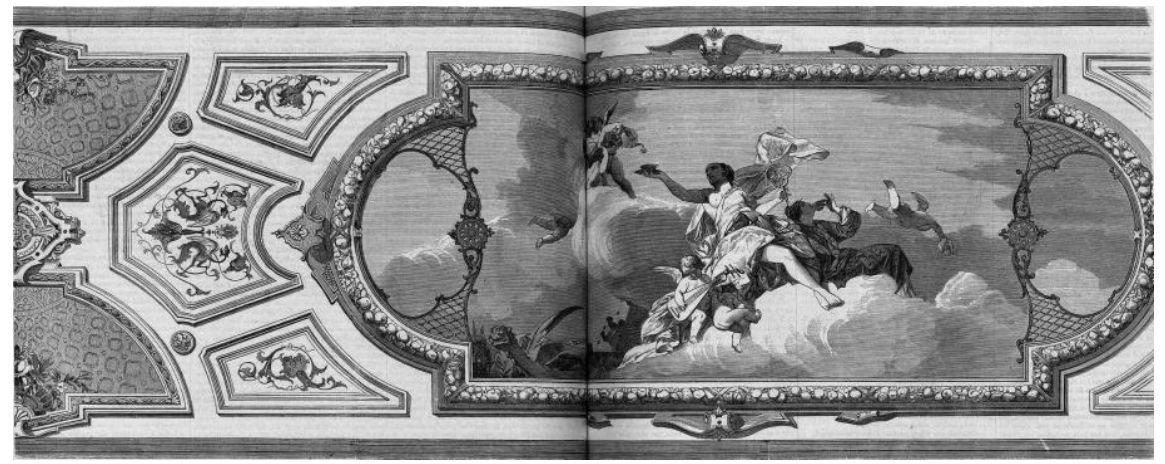

Fig. 2. La alegoría del Té. Techo pintado por José Vallejo y Galeazo, con ornamentación de Augusto Ferri y Giorgio Busato, en el café de Fornos de Madrid. Fuente: La Ilustración de Madrid, Madrid, 27 de junio de 1870 (Biblioteca de Humanidades María Moliner, Zaragoza).

\footnotetext{
${ }^{14}$ Pintor nacido en Málaga en 1821, fallece en Madrid en 1882 (Ossorio y Bernard, 1869: 263-264).

${ }^{15}$ Como señala María de los Ángeles Pérez Samper, el chocolate, el café y el té eran en el siglo XVIII bebidas de prestigio, de signo social elevado, que generaron tales expectativas y deseos, que acabaron por difundirse y popularizarse. Las tres eran artículos exóticos, que venían de países lejanos. Así, el cacao era originario de América (y en el siglo XVI se introdujo en nuestro país), el café de Arabia y el té era traído de la China y de la India (luego se extendió a otros países como Japón, y a mediados del siglo XVIII dominaba en la sociedad inglesa) (Pérez, 2000: 158-160).

${ }^{16}$ Para el conocimiento de estos pintores escenógrafos, véase, entre otras publicaciones (Ossorio y Bernard, 1869: 98 y 246-247).
} 
Además, en la planta baja comprendía una sala reservada para las señoras, que estaba adornada con el mismo estilo y con cuatro pinturas de Balaca que simbolizaban las estaciones (La Nación, 1870: 3). En su planta entresuelo disponía de un restaurant (compuesto de varios salones), que alcanzó una gran notoriedad debido a los banquetes que en él se organizaban, muchos de los cuales estuvieron presididos por personajes ilustres de la actualidad. De hecho, el salón para café era considerado como la "Cámara popular del establecimiento, mientras que el restaurant era el Senado" (La Época, 1879: 1).

La prensa encomiaba el acierto con el que los hermanos Fornos habían sabido armonizar el buen servicio con las exigencias del arte (Gil Blas, 1870: 3). Además, tras los años de la Revolución (cuando los cafés habían sido principalmente "teatro de tumultos y de conspiraciones" contra el régimen instaurado) el Fornos tenía más bien el carácter pacífico de una tertulia que daba cabida a todos (La Ilustración Española y Americana, 1879: 242).

No obstante, en sus primeros años de existencia fue célebre porque en sus mesas se discutía de política (comprometida con los principios del liberalismo). Uno de sus más asiduos parroquianos había sido Manuel Ruiz Zorrilla durante el período en que fue presidente de las Cortes y ocupó la presidencia del gobierno (La Igualdad, 1871: 2). Este político hizo un verdadero reclamo a este establecimiento cuando lo citó en el famoso discurso de "los puntos negros" de la política pronunciado el 25 de noviembre de 1870 a bordo de la Villa de Madrid (cuando fue a buscar a Amadeo de Saboya para ofrecerle la Corona de España) (Higueras, 2014: 324-325), suponiendo que en él "toda molicie corruptora tenía su asiento y el sibaritismo su altar" (La Época, 1887: 2). Igualmente, fue frecuentado por otros políticos (principalmente de concepción republicana) y periodistas distinguidos del momento como Ramón Chíes y José Guisasola (Las Dominicales, 1894: 1).

También presidió algunos de sus banquetes Segismundo Moret siendo ministro de Hacienda en el primer gobierno del reinado de Amadeo I (18711873), sobresaliendo entre ellos el que congregó al abogado y escritor cubano Miguel de Figueroa y García y a sus amigos de la Academia de Jurisprudencia y Legislación, el 30 de diciembre de 1871 (La Discusión, 1872: 2); el organizado en honor del político Emilio Castelar, por algunos diputados, senadores y periodistas republicanos, el 29 de diciembre de 1872 (La Nación, 1872: 2); o el 
verificado por los miembros de la sociedad abolicionista para festejar el resultado de la ley de abolición de la esclavitud en Puerto Rico, el 24 de junio de 1873 (La Discusión, 1873: 1). Sin embargo, a partir de entonces fueron desapareciendo de los banquetes celebrados en el Fornos los retazos revolucionarios que habían caracterizado años atrás a los partidarios de ésta (El Pensamiento español, 1871: 3).

Pocos años después de su inauguración, y respondiendo al espíritu de emprendimiento industrial de los hermanos Fornos, fue reformado en el mes de septiembre de 1879, bajo la dirección de los artistas Ramón Guerrero -padre de la admirada actriz- y Emilio Sala (El Liberal, 1879: 2-3). El 17 de octubre de ese año reabrió nuevamente al público, que quedó sorprendido ante la riqueza de su decorado, la belleza de sus frescos y su comodidad (El Imparcial, 1879: 3-4, y El Globo: 1879: 3). La acción del tiempo había deteriorado visiblemente sus adornos por lo que fueron sustituidos por otros, conservándose la obra de Vallejo y Galeazo. De este modo, sus paredes fueron ornadas con una naturaleza exuberante y rica propia del paisajista Antonio Gomar, quien plasmó los encantadores cármenes de Andalucía. El techo fue primorosamente decorado con cuatro lienzos del admirado artista alcoyano Emilio Sala Francés que representaban alegorías, de inspiración greco-romana, alusivas al fin del establecimiento: un Clásico puchero (en relación con nuestra cocina popular), el Café, el Té y el Vino. En opinión de Adrián Espí, fueron resueltos con una gracia poco común en el género, con una movilidad y vitalidad extraordinarias y con una técnica dibujística y luminosa pocas veces superada (Espí, 1975: $114)^{17}$. También pertenecía a este artista un lienzo (ubicado junto a la puerta de entrada) que tenía como protagonista a Mercurio (representado por una mujer con parte de su cuerpo descubierto) con el caduceo en una mano y en la otra una cafetera (Fig. 3).

La obra referida al Café mostraba una musa o poetisa, recostada en un sillón y en actitud pensativa, con una pluma en su mano diestra (Fig. 4) ${ }^{18}$. Sobre la mesa, junto a las cuartillas, humea una taza de café, y delante de ella, sen-

\footnotetext{
${ }^{17}$ La obra de este artista (1850-1910), que también decoró otros cafés (como la Cantina Americana, Carrera de San Jerónimo) ha sido estudiada en esta publicación.

${ }^{18}$ La figura 4 pertenece a los fondos del Instituto del Patrimonio Cultural de España (autor de la fotografía: J. Laurent y Cía, fecha de la toma: 1879-1896, y signatura VN-07198).
} 
tado, o más bien acurrucado en la nube que forman los vapores que se elevan de la tierra al amanecer un travieso geniecillo o putti le vierte café en el tintero, mientras que otro, envuelto en tules y con alas de pensamiento, viene a traerle esa inspiración que se siente en las primeras horas de la mañana, después de haber pasado la noche en vela. La lámpara que había ardido toda la noche se apaga a la primera claridad del alba. Al mismo tiempo, sobre el barrote que sostiene una cortina, viene a posarse un grupo de pájaros, cuyo plumaje está aún húmedo por el rocío de la madrugada (La Unión, 1879: 1-2).
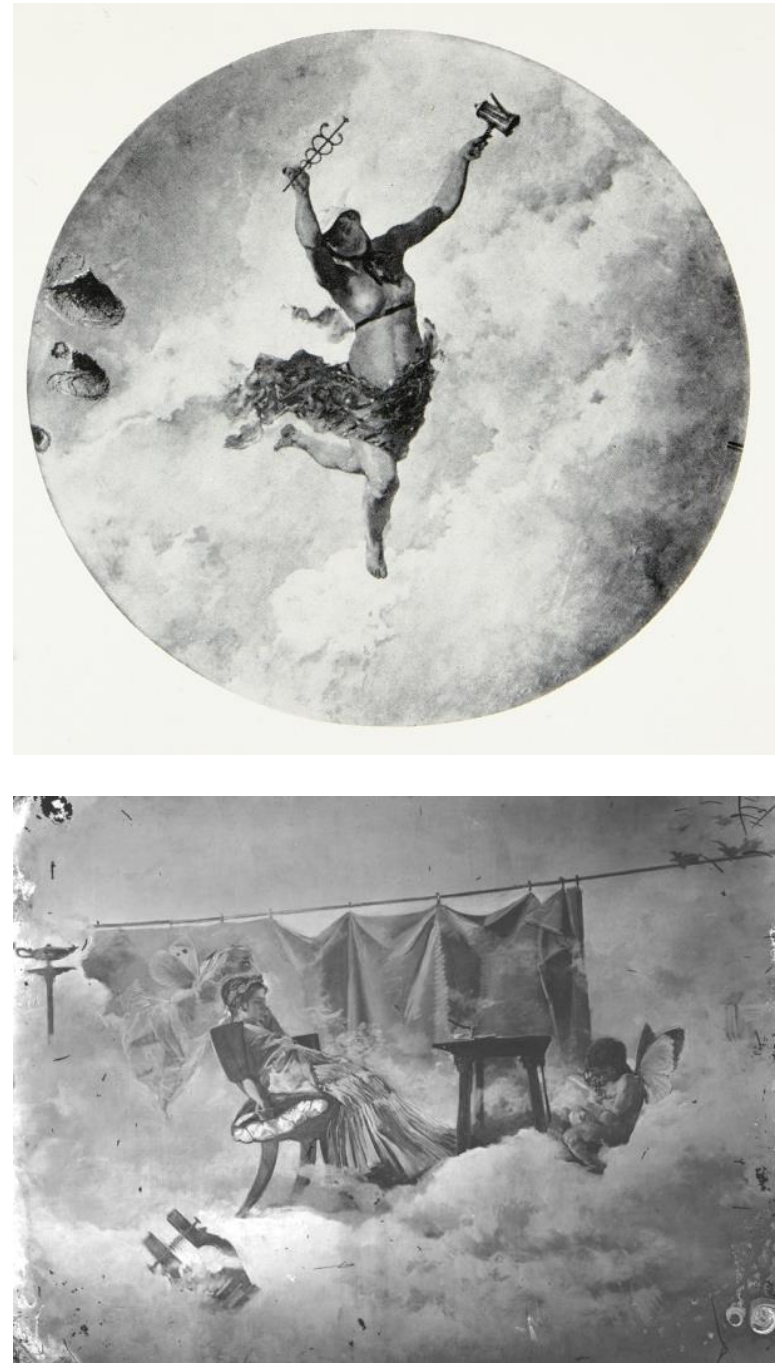

Fig. 3. Figura de Mercurio para la decoración del café de Fornos, por Emilio Sala Francés, 1879. Fuente: A. Espí Valdés (Biblioteca de la Diputación Provincial de Zaragoza).

Figura 4. La alegoría del Café. Lienzo pintado por Emilio Sala para el techo del café de Fornos de Madrid, fotografía por J. Laurent y Cía. Fuente: Ruiz Vernacci (Instituto del Patrimonio Cultural de España, Ministerio de Educación, Cultura y Deporte). 
En cuanto al Té, aparecían tres figuras femeninas que representaban a Inglaterra, China e India. La primera de ellas estaba saboreando la infusión y sus dos compañeras la contemplaban. El Vino se hallaba simbolizado por tres alegres bacantes (coronadas de hiedra) y una de ellas intentaba ceñir una corona a la frente de Sileno. En otro se plasmaba la Cocina española, con una mujer que estaba cociendo garbanzos (alimento tradicional de esta tierra), mientras que un pinche francés con su gorro y mandil blanco le hacía una mueca burlándose de nuestra cocina. Por su parte, los helados, la repostería y el servicio estaban representados por figuras desnudas sobre fondo de oro (La Época, 1879: 3).

Este salón fue iluminado por profusión de luces, ornado con hermosas estatuas de hierro (traídas de París, que soportaban candelabros de bronce dorado, de catorce bujías cada uno) y amueblado con un mostrador (de nogal y revestido de espejos), cortinas de seda y divanes de terciopelo carmesí (Fig. 5). Por su parte, el restaurant tenía cuadros que plasmaban escenas de principios de siglo, debidas al pincel del artista ciudadrealeño Joaquín Araujo, que dio carácter a los tipos de aquella época. Contaba con tres comedores y las paredes del principal fueron decoradas con tapices de Germán Zuloaga, que presentaban escenas de caza. Además, esta pieza del entresuelo comprendía un gabinete (denominado La Farmacia) que exhibía caricaturas de Manuel Luque y Daniel Perea, que reproducían personajes curiosos de la sociedad de entonces.

La prensa madrileña reseñaba que este establecimiento, tras esta transformación acometida con arte y elegancia, resultaba superior a otros de su clase en el extranje-

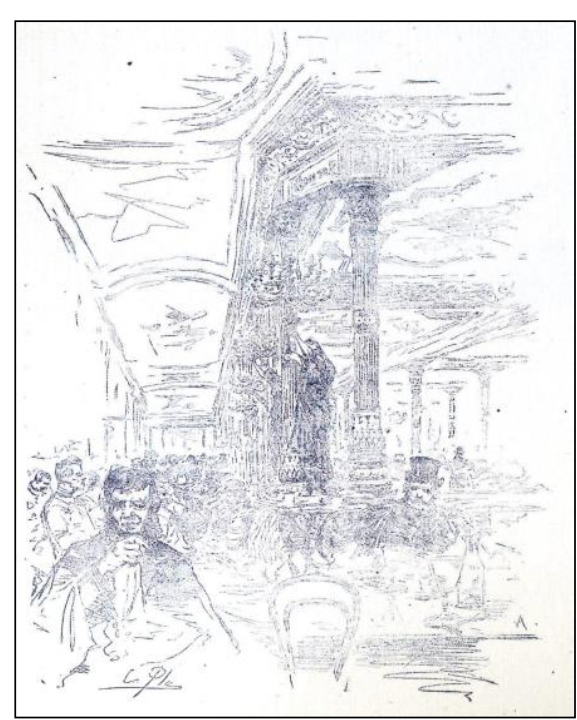

Figura 5. Aspecto parcial del interior del café de Fornos, 1884. Fuente: El Globo, Madrid, 4 de marzo 1884 (Biblioteca de la Diputación Provincial de Zaragoza). ro. También se decía de él que era "un museo con las reputadas firmas de Sala, Vallejo, Gomar, Araujo, Perea, Guerrero y de otros artistas que compitieron en dar a los adornos un sello de buen gusto que armonizaba las diversas artes" ( $\mathrm{La}$ Ilustración Española y Americana, 1879: 242). 
Su tertulia más famosa fue llamada La Farmacia porque en ella, como precisa el cronista madrileño Antonio Velasco Zazo, había de todo, como en botica: políticos, hombres de negocios, banqueros, artistas ${ }^{19}$, músicos ${ }^{20}$, médicos, periodistas, literatos, cómicos, autores dramáticos y toreros (entre ellos, Frascuelo y Lagartijo) (Velasco, 1945: 31). En los años de la restauración de Alfonso XII (cuando este café alcanzó su máximo esplendor) ${ }^{21}$ estuvo presidida por el empresario Felipe Ducazcal y a ella acudían los escritores y periodistas Leopoldo Alas Clarín, Javier de Burgos y Sarragoiti y Luis Taboada, entre otros (Espina, 1995: 236-237, y La Ilustración artística, 1900: 107). Sus tertulianos de mayor relieve llegaron a comienzos del siglo XX con Antonio Machado, Ramón María del Valle-Inclán, Azorín, Pío Baroja, Alejandro Sawa y esporádicamente Miguel de Unamuno (La España, 1916: 10)22. En esas fechas también se relacionaban cotidianamente en este café "los cruzados del humor" (desde las dos de la madrugada -hora en que se cerraban los teatros- en adelante), como se conocía al grupo conformado por los dramaturgos Enrique García Álvarez y Manuel Paso y sus amigos (entre ellos, el dibujante Pedro Rojas y el caricaturista Leal da Câmara) (Zamacois, 1935: 18).

\section{El Madrid que se va: declive y cierre del Fornos.}

El 1 de octubre de 1887 este antiguo café-restaurant celebró su segunda reapertura después de una reforma (llevada a cabo durante ese verano) que conservó su primitivo aspecto aunque renovado y mejorado ${ }^{23}$. Así, las columnas se doraron nuevamente con oro, blanco y amarillo, los brazos de los candelabros fueron rebajados para que la luz no dañase los techos y las cornisas,

\footnotetext{
${ }^{19}$ El pintor valenciano José Benlliure (1855-1937), hermano del escultor Mariano Benlliure, fue uno de los parroquianos habituales de este café (La Ilustración artística, 1897: 3).

${ }^{20}$ Julián Gayarre (1844-1890), acompañado por el guitarrista Luis Pérez de la Tiorba, fue uno de los tenores que cantó en este café (El Imparcial, 1928: 13).

${ }^{21}$ A este respecto, es interesante decir que la prensa de la época recoge que: “De este café salieron una fría noche del mes de diciembre de 1875, los primeros grupos de caballeros que vitorearon en las calles a Don Alfonso, a quien Martínez Campos acababa de proclamar rey en los campos de Sagunto" (El País, 1908: 3).

${ }^{22}$ En este sentido, cabe mencionar que el periodista Julio Burell escribió el famoso artículo titulado "Cristo en Fornos" (1894), que señaló su definitiva aceptación en los círculos periodísticos y en los cenáculos de progresismo político. (Heraldo de Madrid, 1930: 9) y (Conde, 1985: 33 y 37). ${ }^{23}$ En la sala del café sólo se conservaron intactas las obras de Sala y de Gomar (La Unión, 1887: 2).
} 
y se colocaron espejos en la planta entresuelo (El Liberal, 1887: 3). Igualmente, se restauraron los motivos ornamentales y los tapices de las salas.

Esta obra fue emprendida por Manuel Martínez ${ }^{24}$, que estaba casado con una de las hermanas de los fundadores del establecimiento, a quien lo tenían arrendado. Todos los trabajos se realizaron bajo la dirección de los artistas Ríos y Carmena (La Época, 1887: 2). A causa del cambio en su gestión, su reputación fue languideciendo (especialmente la de su restaurant y sus tertulias); de ahí que sus antiguos propietarios (los hermanos Fornos) decidieran ponerse al frente del mismo en el mes de marzo de 1890. Con la finalidad de impulsar su negocio, introdujeron novedades como las denominadas "cenas módicas" (a dos pesetas el cubierto) y el servicio de coches de alquiler para sus parroquianos (a razón de una peseta la carrera y dos la hora) (La Monarquía, 1890: 3). De este modo, el Fornos (calle de Alcalá, núm. 19) volvió a recuperar su esplendor y continuó siendo uno de los preferidos por el público y el rendez-vous de la sociedad escogida.

En estos momentos, Manuel Fornos fue noticia de actualidad por haberse afiliado al partido liberal (originalmente Partido Liberal-Fusionista, fundado por Práxedes Mateo Sagasta), el 23 de septiembre de 1890 (El Imparcial, 1890: 1). Este hecho explicaría que en la prensa periódica se comentase que el "Fornos había entrado en el partido fusionista" y que esto "iba por las veces que el partido fusionista había entrado en este establecimiento" (El País, 1890: 1). Esta publicidad fue beneficiosa para la industria y, concretamente, de cara a la celebración de banquetes (que congregaron fundamentalmente a los republicanos de su distrito) como el organizado el 11 de febrero de 1891 por los republicanos del Centro para conmemorar el XVIII aniversario de la proclamación de la República, que fue presidido por Nicolás Salmerón Alonso (Heraldo de Madrid, 1891:3).

A finales del siglo XIX en el Fornos seguía reuniéndose lo más granado de la literatura y de la política del momento, así como se hablaba y discutía mucho de arte (Fig. 6) ${ }^{25}$. Fue en él donde el galerista Manuel Vilches (Córdoba, 1870-Madrid, 1940), fundador del Salón Vilches, también conocido como Sala o Casa Vilches (calle del Príncipe, núms. 19 y 21), empezó a vender sus cua-

\footnotetext{
${ }^{24}$ Manuel Martínez, que desde esta fecha y hasta finales de 1889 estuvo al frente de esta industria, falleció el 4 de abril de 1890 (El Liberal, 1890: 3).

${ }^{25}$ La figura 6 pertenece a los fondos de la Biblioteca Nacional de España y es propiedad de la misma (con fecha de recepción de 1960 y con signatura 17/229/22).
} 
dros y, en concreto, de artistas como Jaime Morera, Eliseo Meifrén y José Lupiáñez (Romano, 1928: 17).

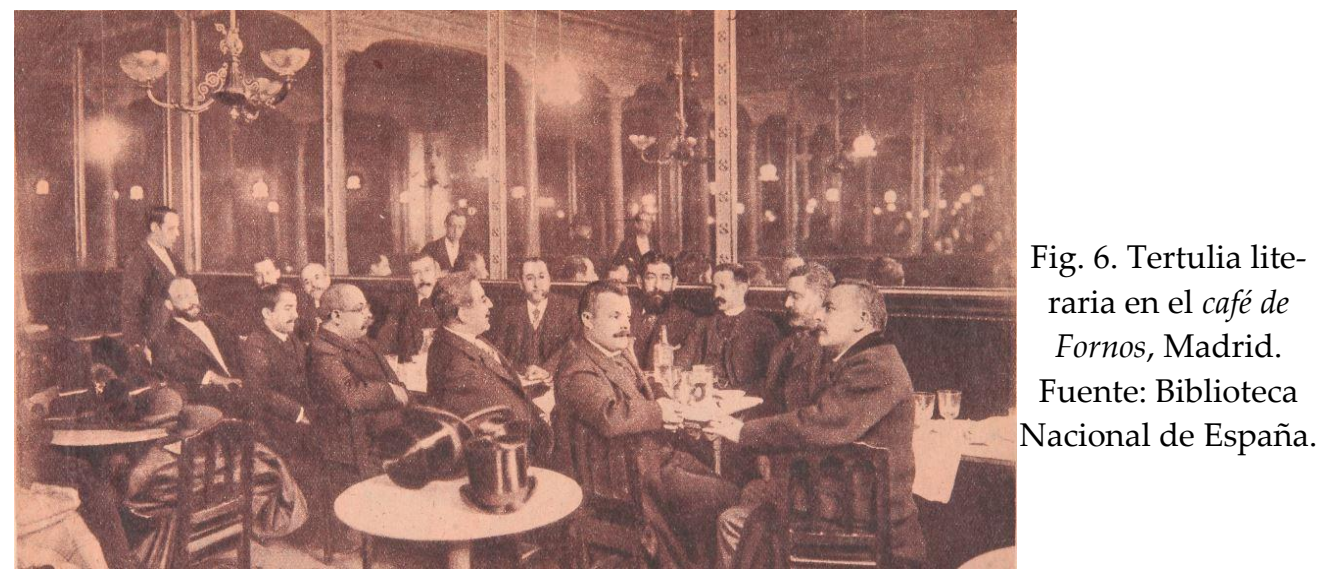

En mayo de 1900, por disolución de la sociedad mercantil que explotaba este café, quedó exclusivamente como responsable del mismo Manuel Fornos, que era uno de sus copropietarios (El Imparcial, 1900: 3). Cuatro años después, y probablemente a causa de las dificultades económicas por las que estaba atravesando su negocio, este industrial decidió poner fin a su vida a sus sesenta años de edad (el 13 de julio de 1904) ${ }^{26}$. Su fallecimiento fue muy sentido en la ciudad, donde contaba con un gran número de amigos. El Fornos ya no era ni la sombra de lo que había sido cuando se fundó (La Época, 1904: 1). Felipe Caramanzana, testamentario del difunto, asumió provisionalmente su gestión (El Globo, 1904: 2).

Antes de este lamentable suceso, fue escenario de renombrados banquetes como el que tuvo lugar en honor del novelista Benito Pérez Galdós, el 13 de marzo de 1904 (El Imparcial, 1904: 3); o el dedicado, el 13 de diciembre de ese año, al pintor guipuzcoano Ignacio Zuloaga. Entre las personalidades del mundo artístico y literario (algunos de ellos destacadas figuras de la generación del 98) que asistieron se encontraban Santiago Rusiñol, Joaquín Dicenta, Agustín Querol, Luis Morote, Ramiro de Maeztu, José Ma․ Salaverría y Pío Baroja (El Imparcial, 1904: 1).

\footnotetext{
${ }^{26}$ Manuel Fornos dejó sus bienes a su amiga Josefa Pilar Fernández Prieto (El Día, 1904: 2) y (Heraldo de Madrid, 1904: 1).
} 
En marzo de 1906 se hizo cargo de este café uno de los sobrinos de sus fundadores, José Martínez Fornos (conocido como Pepito Fornos)27, quien introdujo mejoras en su servicio con el fin de volver a colocarlo en el nivel de sus buenos tiempos (El Imparcial, 1906: 4). Sin embargo, el destino le dio nuevamente un duro revés. Así, en el mes de octubre de 1907, una sentencia (dictada por la sala primera del Tribunal Supremo) dispuso su desahucio por haber expirado el término que había dado la propietaria del inmueble (donde se hallaba situado) para la rescisión de su contrato. Por tanto, atendiendo a la misma, se determinó su clausura (El País, 1907: 4), que se produjo el 7 de enero de $1908^{28}$, aunque fue sólo por tres días, dado que el día 10 de ese mismo mes volvió a abrirse al público, una vez superadas las diferencias entre la dueña de la casa y la familia Fornos (La Época, 1908: 3). A pesar de los esfuerzos realizados, el 16 de agosto de 1909 cerró definitivamente sus puertas por razones económi$\operatorname{cas}^{29}$, tras haber sido durante muchos años un foco de actividad intelectual ${ }^{30}$.

\section{El recuerdo del Fornos.}

El 5 de enero de 1910, Antonio Labraña, que había sido el encargado de este establecimiento durante muchos años, abrió un café-restaurant (calle de Alcalá, núm. 23, en el local en el que había estado el restaurant -o los comedores- del Fornos), con todas las características del antiguo, de tan gratos recuerdos para la sociedad madrileña (El Imparcial, 1910: 3). Los servicios y la cocina respondían a la tradición de la casa. El salón del café fue decorado por el artista José Arija (La Correspondencia de España, 1910: 5), en cuyas paredes se representaron alegóricamente las estaciones y el Día y la Noche (La Mañana, 1910: 1). Con su apertura, el Fornos no "había desaparecido del todo", y el caférestaurant Labraña era, en cierto modo, una continuación de él.

\footnotetext{
27 Pepito Fornos falleció, a la edad de 35 años, el 21 de noviembre de 1907 (La Época, 1907: 3).

${ }^{28}$ Sin embargo, el restaurant del Fornos se mantuvo abierto (El Imparcial, 1908: 2) y (La Época, 1908: 3).

${ }^{29} \mathrm{Su}$ clausura respondió a las subidas en el alquiler del local y a las imposiciones establecidas por Juan de la Cierva (ministro de la Gobernación) en relación con el cierre temprano de este tipo de establecimientos (La Correspondencia de España, 1909: 7). En la prensa madrileña se comentó que los cuadros y las estatuas del café se conservaron en la quinta del Hipódromo de Pedro Villar (Castrovido, 1920: 1).

${ }^{30}$ Cuando desapareció este café, José Fornos (llamado popularmente Pepe Fornos, hermano de Manuel y Carlos), dueño de este negocio, se apartó de la vida pública. Falleció el 3 de febrero de 1913 (El Liberal, 1913: 3).
} 
Poco tiempo después, el 3 de mayo de $1910^{31}$, se verificó la inauguración en los magníficos locales del desaparecido Fornos de un nuevo café denominado Gran Café (calle de Alcalá, núm. 25, esquina con la de Peligros, núm. 1) (aunque seguía siendo conocido por los ciudadanos por su primitivo nombre), que se mantuvo hasta julio de 1920 (La Correspondencia de España, 1910: 5). La sociedad gestora introdujo importantes reformas y un restaurant (en la planta de entresuelo), aunque la clientela no sería la misma.

El restaurant del Gran Café (antiguo Fornos, como así se hacía referencia a él en la prensa) era elegido, por su espléndido servicio gastronómico, para la celebración de banquetes en honor de insignes personalidades. De este modo, cabe destacar el ofrecido al pintor murciano Inocencio Medina Vera antes de su partida para Buenos Aires (donde fue contratado por la revista La semana universal), el 23 de octubre de 1911 (La Mañana, 1911: 4); o el organizado para el poeta madrileño Emilio Carrère, por varios de sus amigos y admiradores, el 7 de enero de 1912, con el fin de obsequiarle por el triunfo literario y editorial que había obtenido con su último libro El encanto de la bohemia (El Imparcial, 1912: 5).

En ese año de 1910, sólo en la Puerta del Sol y calles aledañas existían hasta sesenta y cinco cafés, siete de ellos en la misma plaza (López, 1999: 84). Sin embargo, alguno de ellos pronto se batió en retirada. Así, el Suizo tuvo que cerrar sus puertas el 16 de julio de 1919 por derribo de la finca en la que se asentaba, anclada en la esquina de las calles de Alcalá y Sevilla, llevándose consigo muchas historias y recuerdos de Madrid (Parlante, 1919: 25). Su inmueble fue demolido y en su solar se construyó el edificio del Banco Bilbao Vizcaya (construido por el arquitecto Ricardo Bastida, 1919-1923) ${ }^{32}$. Aquel irregular cruce de calles -Alcalá, Peligros ${ }^{33}$ y Sevilla- donde se emplazaba había sufrido una profunda transformación. Todo había cambiado y ya no quedaba más que el Fornos como "último superviviente de aquellas esquinas" (y tampoco era el café de hace años) (La Acción, 1919: 3).

\footnotetext{
${ }^{31}$ La viuda de Murga, propietaria de la finca que ocupó el Fornos, tan pronto como éste cesó decidió alquilar su local para café, como hasta ese momento había sido (El Liberal, 1909: 3).

32 En la actualidad, en este edificio se encuentra la Conserjería de Medioambiente, Administración Local y Ordenación del Territorio de la Comunidad de Madrid.

${ }^{33}$ A principios del año 1920 se acometió la alineación de la calle de los Peligros con la finalidad de ensancharla, dado que era muy angosta para su mucho tránsito (La Construcción Moderna, 1920: 7).
} 
Este fue el sentido adiós que el poeta Manuel Machado dio al Suizo (y en el que se alude también al Fornos):

[...]. Yo nunca fui, sin embargo, parroquiano asiduo del Suizo. Para serlo había que tener, por lo menos, esa cierta edad que yo no he alcanzado todavía. Así como Fornos, el antiguo, fue el bullicioso, alegre y escandaloso burdel de la juventud del último tercio del siglo XIX, el Suizo se mantuvo siempre como el honesto café de la alta burguesía madrileña, serio, senatorial y tranquilo [...].

[...] El buen café Suizo, anticuado de pronto, sobrevivía tristemente a sus esplendores pasados. Y es cierto que ha venido a caer con oportunidad (Machado, 1919: 3).

Al cesar la industria del Suizo, se trasladaron al Fornos varias de sus reuniones, una de ellas la formada en torno a Francisco Aguilera (capitán general de Madrid), que solía congregarse con sus tertulianos donde tiempo antes se había sentado el anarcosindicalista Ángel Pestaña durante su estancia en la ciudad, y donde, por la tarde, se encontraban el periodista y escritor propagandista Mauro Bajatierra y sus amigos (Castrovido, 1920: 1).

El 13 de julio de 1920 se cerró el local del antiguo café de Fornos para ser transformado en un moderno y lujoso cabaret, al estilo de los de las principales capitales europeas, llamado Fornos Palace (calle de Alcalá, núm. 25) ( $\mathrm{La}$ Acción, 1920: 1) y bajo la dirección del gerente Joaquín Llovet (La Correspondencia de España, 1920: 5). Su inauguración pública tuvo lugar el 4 de diciembre de ese año, y fue acogido como lugar de esparcimiento y de recreo nocturno ( $\mathrm{La}$ Voz, 1920: 6).

Posteriormente, la sociedad Hijos de Honorio Riesgo adquirió este lugar y acometió obras de reforma para destinarlo a café-restaurant, que nombraría con su apellido: Riesgo. Fue inaugurado oficialmente el lunes 22 de octubre de 1928 y persiguió convertirse en el centro de reunión de la distinguida sociedad madrileña (Fig. 7) (Mundo Gráfico, 1928: 3). Tenía plantas sótano (cocina y almacén, entre otras dependencias), baja (donde había un amplio salón para café y restaurant, que se hallaba delimitado por hileras de columnas, entre las que se disponían mesas de mármol con sus sillas de madera) y entresuelo (para billares) (El Imparcial, 1928: 8). Del antiguo Fornos sólo conservaba el espacio, todo lo demás era distinto. 
En mayo de 1932 una compañía de seguros presentó al municipio el proyecto del edificio que se levantaría en el solar de la casa que había ocupado el Fornos, en la calle de Alcalá esquina con la de la Virgen de los Peligros (El Sol, 1932: 5) ${ }^{34}$. En él, el Banco Vitalicio de España (propietario de la misma desde 1923) ${ }^{35}$ estableció su nueva sede en 1941 y, en su planta baja, Honorio Riesgo instaló el café-bar-restaurante Riesgo (calle de Alcalá, núm. 23) ${ }^{36}$.

Un afán renovador invadía la época. Ese Madrid que estaba desapareciendo correspondía, en opinión de Pío Baroja, un poco al Madrid de Larra y de Espronceda, al de Zorrilla y de Fernández y González, al de los policías como Chico y de los conspiradores como Aviraneta. Pertenecía también "a la época de Galdós y Echegaray, de la cuarta del Apolo (en referencia a la cuarta sesión de este teatro), del Madrid Cómico y del café de Fornos lleno, con Salvador María Granés ${ }^{37}$ que insultaba, con Cavia que bebía y con Dicenta que disputaba" (Baroja, 1933: 5).

Este célebre café estuvo unido durante años a muchos episodios relevantes de la vida madrileña y tuvo un notable impacto en su entorno urbano, en el que proliferó la presencia cultural. Como bien señala Antonio Velasco, en él se condensa toda una época como centro de artistas y literatos y epicentro de la bohemia histórica (Velasco, 1934: 3). Los espejos del Fornos vieron los rostros de muchos personajes del Madrid de Alfonso XII y de la Regencia, pero de él no queda más que el recuerdo; aquí evocado con esta aportación.

\footnotetext{
${ }^{34}$ En el mes de enero de 1933 se anunció en la prensa madrileña la liquidación de los enseres (divanes, mesas, sillas, cafeteras y demás objetos) del establecimiento. Las obras de derribo de las casas llamadas "de Fornos" comenzaron un mes después ( $L a V o z, 1933: 6$ ) y (Anasagasti, 1933: 3).

${ }^{35}$ El edificio para el Banco Vitalicio de España fue proyectado por los arquitectos Eusebio Bona y Luis Mosteiro.

${ }^{36}$ La liquidación de concierto de esta industria tuvo lugar el 4 de noviembre de 1948 (A.V.M., 1948). En la actualidad, la planta baja de este inmueble (calle de Alcalá, núm. 21, esquina con la calle Virgen de los Peligros) se halla ocupada por una franquicia de una cadena internacional de café.

${ }^{37}$ Emilio Fernández Corujedo hablaba de la "simpática peña" que tenían en el desaparecido café de Fornos y a la que "acudían con alguna asiduidad Alejandro Lerroux, Arniches, Salvador María Granés y algunos más” (Sánchez, 2017: 419).
} 


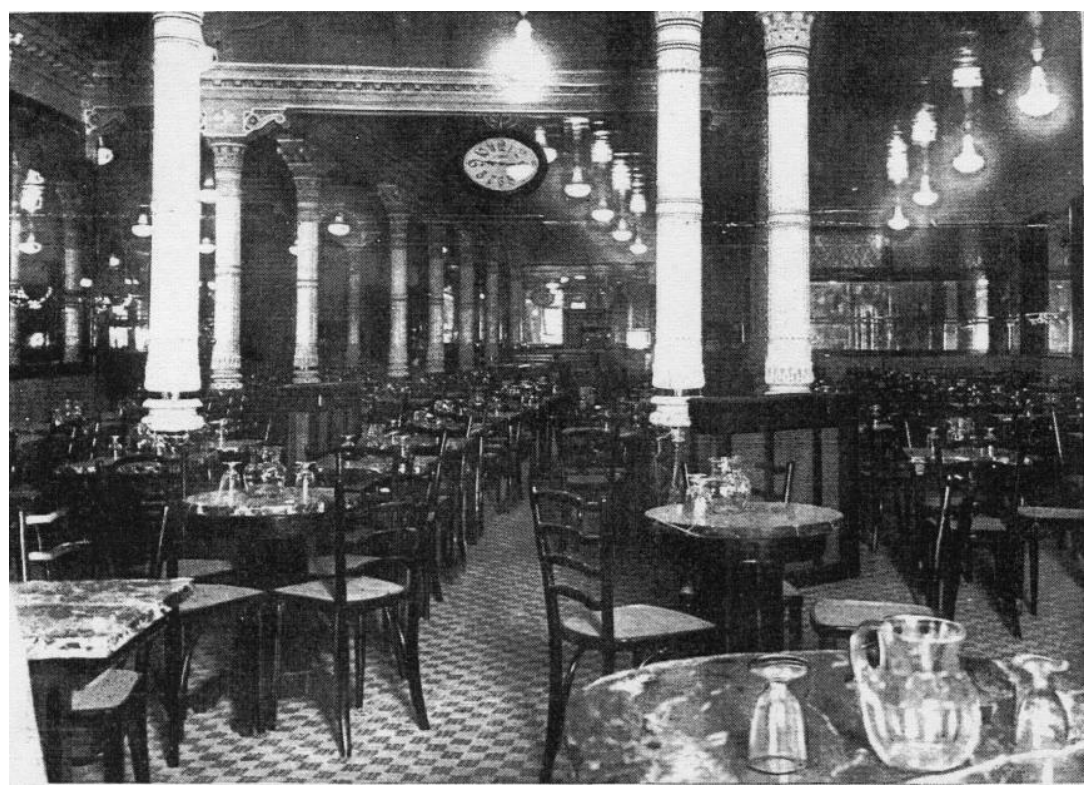

Fig. 7. Vista parcial del interior del café Riesgo, 1928. Fuente: Mundo Gráfico, Madrid, 24 de octubre de 1928 (Biblioteca de la Diputación Provincial de Zaragoza).

\section{Bibliografía.}

ÁLBUM SALÓN (1901). "Fornos", 1 de enero de 1901, p. 15.

ANASAGASTI, T. (1933). “Arquitectura del momento. La piqueta en Fornos" en La Libertad, 10 de febrero de 1933, p. 3.

ANTIGÜEDAD DEL CASTILlo-OlivareS, M. D. (1998). “El museo de la Trinidad, germen del museo público en España" en Espacio, Tiempo y Forma. Serie VII, Historia del Arte, t. 11, pp. 367-396.

ARChIVO DE VILla DE MAdRID [A.V.M.]. Secretaría, Sección 24, Caja 380, expediente núm. 88: "Expediente sobre concesión de licencia para apertura de un espectáculo en la casa no 20 de la calle de Alcalá", 1910.

Secretaría, Sección 9, Caja 285*, expediente núm. 112: “Impuesto sobre consumos y servicios de lujo, establecimiento café-bar-restaurante Riesgo en calle Alcalá, núm. 23", 1948.

BAROJA, P. (1933). "Las calles siniestras" en Ahora, 19 de febrero de 1933, p. 5.

BÉCQUER, G. A. (1870). “Madrid Moderno. Techo pintado por el señor Vallejo con ornamentación de los sres. Ferry y Busato en el nuevo café de Fornos" en La Ilustración de Madrid, 27 de junio de 1870, pp. 8-9 y 15-16. 
BONET CORREA, A. (2012). Los cafés históricos. Madrid: Cátedra.

CABEllo LAPIEDRA, L. M‥ (1933). “Las casas de Fornos que desaparecen” en La Construcción moderna, 1 de mayo de 1933, p. 15.

Castrovido, R. (1920). "Los cafés en Madrid. El cierre de Fornos" en La Voz, 14 de julio de 1920, p. 1.

Castrovido, R. (1926). "Casinos, círculos, clubs" en Alrededor del mundo, 27 de noviembre de 1926, p. 590.

CONDE GUERRI, Ma. J. (1985). “Julio Burell, el otro ministro de “Luces de Bohemia"”" en Estudios humanísticos. Filología. Universidad de León, no․ 7, pp. 31-42.

DIARIO CURIOSO, ERUDITO, ECONÓMICO Y COMERCIAL (1787). "Noticias particulares de Madrid. Noticias sueltas", 23 de septiembre de 1787, p. 354.

DIARIO DE MADRID (1788). "Noticias particulares de Madrid. Ventas", 16 de agosto de 1788 , p. 807.

DIARIO DE MADRID (1839). “Anuncios”, 1 de abril de 1839, p. 2.

DIARIO OFICIAL DE AVISOS DE MADRID (1852). “Pérdidas”, 11 de mayo, 1852, p. 2.

_ (1867). "Variedades", 12 de junio de 1867, p. 4.

(1870). “Generales", 22 de julio de 1870, p. 4.

(1873). "Espectáculos", 25 de noviembre de 1873, p. 4.

EL CLAMOR PÚBLICO (1854). "Sección política", 1 de agosto de 1854, p. 1.

EL CONTEMPORÁNEO (1861). “Gacetilla de la capital”, 30 de marzo de 1861, p. 4.

EL DÍA (1904). "Intento de suicidio de D. Manuel Fornos", 13 de julio, 1904, p. 2.

EL ECO DEL COMERCIO (1838). "Remitido", 1 de enero de 1838, p. 4.

EL GLOBO (1879). "Variedades. Inauguración del café de Fornos", 18 de octubre de 1879 , p. 3.

EL GLOBO (1904). "El sorteo de Navidad”, 24 de diciembre de 1904, p. 2.

EL HERALDO (1845). “Gacetilla de la capital”, 4 de junio de 1845, p. 4.

EL IMPARCIAL (1879). "El café de Fornos", 18 de octubre de 1879, pp. 3-4. (1884). "Ateneo", 1 de febrero de 1884, p. 2.

(1890). "Miscelánea política", 25 de septiembre de 1890, p. 1.

(1900). "Sección de noticias", 30 de mayo de 1900, p. 3.

(1904). "Sección de noticias", 11 de marzo de 1904, p. 3.

(1904). "Banquete a Zuloaga", 14 de diciembre de 1904, p. 1.

(1905). "Sección de noticias", 16 de agosto de 1905, p. 3.

(1906). "Sección de noticias", 17 de marzo de 1906, p. 4.

(1908). “El cierre de Fornos", 7 de enero de 1908, p. 2. 
(1910). “Sección de noticias", 6 de enero de 1910, p. 3.

(1911). "Los Teatros", 16 de abril de 1911, p. 2.

(1912). "Sección de noticias", 5 de enero de 1912, p. 5.

(1919). “Lo típico de Madrid desaparece. Café Suizo", 17 de julio de 1919, p. 4.

(1925). “La vida teatral. Inauguración del Alkázar”, 28 de enero de 1925, p. 3.

(1928). “Del Madrid Moderno. El café de Fornos y su transformación”, 25 de octubre de 1928, p. 8.

(1928). “Del Madrid que se va. El café de Fornos”, 28 de octubre de 1928, p. 13.

EL LIBERAL (1879). "La industria moderna. Fornos", 14 de octubre de 1879, pp. 2-3.

(1887). "Café restaurant Fornos", 2 de octubre de 1887, p. 3.

_ (1890). "Cartera de Madrid", 5 de abril de 1890, p. 3.

(1909). "Noticias", 29 de octubre de 1909, p. 3.

(1913). “Don José Fornos”, 4 de febrero de 1913, p. 3.

El Movimiento CATÓLICO (1897). “El ministro de Hacienda y la comunidad de las Vallecas", 27 de septiembre de 1897, p. 1.

EL PAÍS (1890). "Comentarios", 25 de septiembre de 1890, p. 1.

(1907). “Tribunales", 10 de octubre de 1907, p. 4.

(1908). "El cierre de Fornos", 8 de enero de 1908, p. 3.

EL PENSAMIENTO ESPAÑOL (1871). “Noticias”, 10 de enero de 1871, p. 3.

EL SOL (1932). "Intereses de Madrid", 15 de mayo de 1932, p. 5.

EsPí VALDÉS, A. (1975). El pintor Emilio Sala y su obra. Valencia: Servicio de

Estudios Artísticos. Diputación Provincial de Valencia.

EsPINA, A. (1995). Las tertulias de Madrid. Madrid: Alianza Editorial.

FUENTES, J. F. (2001). “De la sociabilidad censitaria a la sociabilidad popular en la España liberal" en Fuentes, J. F. y ROURA I AuLINAS, Ll. (eds.), Sociabilidad y liberalismo en la España del siglo XIX. Homenaje al profesor Alberto Gil Novales. Lleida: Editorial Milenio.

GIL BLAS (1870). 24 de julio de 1870, p. 3.

HERALDO DE MADRID (1891). “Última hora”, 10 de febrero de 1891, p. 3.

_ (1904). "El café de Fornos", 14 de julio de 1904, p. 1.

(1930). "El insigne Julio Burell", sábado 2 de agosto de 1930, p. 9.

Higueras CASTAÑEDA, E. (2014). Manuel Ruiz Zorrilla (1833-1895). Liberalismo radical, democracia y cultura revolucionaria en la España del siglo XIX (Tesis Doctoral defendida en la Universidad de Castilla-La Mancha y en acceso abierto en: TDX). Ciudad Real. 
LA ACCIÓN (1919). “La piqueta del recuerdo. La esquina del Suizo", 17 de julio de 1919, p. 3. (1920). "Madrid se transforma. El final de Fornos", 13 de julio de 1920, p. 1.

LA CONSTRUCCIÓN MODERNA (1920). "La transformación de Madrid. Obras y derribos", 15 de marzo de 1920, p. 7.

LA CORRESPONDENCIA DE ESPAÑA (1909). “Notas madrileñas. Fornos, cerrado", 17 de agosto de 1909 , p. 7.

_ (1910). "El antiguo Fornos. Café restaurant Labraña", 5 de enero de 1910, p. 5. (1910). “Gran Café", 3 de mayo de 1910, p. 5.

(1920). "Inauguración. El Fornos-Palace", 4 de diciembre de 1920, p. 5.

LA DISCUSIÓN (1872). "Noticias varias", 1 de enero de 1872, p. 2.

(1873). "La división de poderes", 24 de junio de 1873, p. 1.

LA EPOCA (1879). "Fornos", 17 de octubre de 1879, p. 1.

(1879). "Inauguración del café de Fornos", 18 de octubre de 1879, p. 3.

(1887). “Crónicas madrileñas", 2 de octubre de 1887, p. 2.

(1895). "El Círculo de Bellas Artes", 4 de enero de 1895, p. 2.

(1904). “Crónicas breves. La noche de Fornos", 10 de octubre de 1904, p. 1. (1906). "Sección de noticias", 17 de marzo de 1906, p. 4.

(1907). "Noticias generales", 22 de noviembre de 1907, p. 3.

(1908). "El Madrid que se va. El café de Fornos, cerrado", 7 de enero de 1908 , p. 3.

(1908). "Noticias generales", 11 de enero de 1908, p. 3.

LA ESPAÑA (1864). “Gacetilla de Madrid”, 5 de agosto de 1864, p. 4.

(1916). “Los españoles y la guerra. El viaje de Valle-Inclán”, 11 de mayo de 1916, p. 10.

LA ESPERANZA (1866). “Variedades", 29 de diciembre de 1866, pp. 4-5.

LA IGUALDAD (1871). "Intrigas y cabildeos", 19 de abril de 1871, p. 2.

LA ILUSTRACIÓN ARTÍSTICA (1885). "La novela de un periodista", 9 de noviembre de 1885, p. 3.

_ (1897). “José Benlliure”, 13 de septiembre de 1897, p. 3.

(1900). "Javier de Burgos", 12 de febrero de 1900, p. 107.

LA ILUSTRACIÓN ESPAÑOLA Y AMERICANA (1871). 5 de noviembre de 1871, p. 529. (1873). 1 de diciembre de 1873, pp. 723 y 725.

(1879). "Crónica general”, 22 de octubre de 1879, p. 242. 
(1891). “La casa de 'La Equitativa' en Madrid", 22 de febrero de 1891, pp. 107,110 y 112.

LA ILUSTRACIÓN MODERNA (1892). Tomo I. Barcelona: España y compañía editores. LA LIBERTAD (1921). "Guía de Madrid. La calle de Alcalá", 8 de mayo de 1921, p. 4. LA MAÑANA (1910). "Café-restaurant Labraña. De la vida de Madrid", 9 de diciembre de 1910, p. 1.

(1911). “Los pintores españoles. Medina Vera”, 23 de octubre de 1911, p. 4.

LA MONARQUÍA (1890). “Madrid”, 9 de marzo de 1890, p. 3.

LA NACIÓN (1870). "Noticias", 21 de julio de 1870, p. 3.

(1872). "Política", 29 de diciembre de 1872, p. 2.

LA UNIÓN (1879). “Bellas Artes”, 30 de octubre de 1879, pp. 1-2.

(1887). "Fornos", 2 de octubre de 1887, p. 2.

LA VOZ (1920). "Fornos Palace", 4 de diciembre de 1920, p. 6.

(1933). "Anuncios por palabras", 24 de enero de 1933, p. 6.

LAS DOMINICALES (1894). “Un autógrafo de Ramón Chíes”, 16 de noviembre de 1894, p. 1.

LÓPEZ-CORDÓN CORTEZO, Mạ. V. (1976). La revolución de 1868 y la República. Madrid: Estudios de Historia Contemporánea Siglo XXI.

(2004). “Diversión, orden público y acción política: los cafés madrileños en 1791" en GARCíA FERNÁNDEZ, M. y SOBALER SECO, Mํ. Á. (coords.), Estudios en homenaje al profesor Teófanes Egido. Valladolid: Junta de Castilla y León. Consejería de Cultura y Turismo, pp. 345-362.

LÓPEZ MONDÉJAR, P. (1999). Madrid. Laberinto de memorias (Cien años de fotografía, 1839-1936). Barcelona: Lunwerg Editores, S.A.

LORENTE, J.-P. (2009). “QQué es y cómo evoluciona un barrio artístico? Modelos internacionales en los procesos de regeneración urbana impulsado por las artes" en FERnÁNDEZ, B. y LORENTE, J.-P. (eds.), Arte en el espacio público: barrios artísticos y revitalización urbana. Zaragoza: Prensas Universitarias de Zaragoza, pp. 15-38.

MACHADO, M. (1919). “Intenciones. Filosofías de verano. El Cine, El café Suizo" en El Liberal, 18 de julio de 1919, p. 3.

MARTín CAMACHO, F. J. (2008). Los cafés literarios, Espronceda y el Parnasillo. Almendralejo: Excmo. Ayuntamiento de Almendralejo.

MUNDO GRÁFICO (1928), "Inauguración del nuevo Café Riesgo", 24 de octubre de 1928, p. 33. 
OSSORIO Y BERNARD, M. (1868), Galería biográfica de artistas españoles del siglo XIX. Tomo I. Madrid: Imprenta a cargo de Ramón Moreno.

OSSORIO Y BERNARD, M. (1869). Galería biográfica de artistas españoles del siglo XIX. Tomo II. Madrid: Imprenta a cargo de Ramón Moreno.

PARlANTE, J. (1919). "Del Madrid antiguo. El café Suizo desaparece" en La Esfera, 2 de agosto de 1919, p. 25.

PÉREZ SAMPER, Ma․ Á. (2000). “Chocolate, té y café: sociedad, cultura y alimentación en la España del siglo XVIII" en FerRer BENIMELI, J. A. (dir.) y SARASA, E. y SERRANO, E. (coords.), El conde de Aranda y su tiempo. Vol. I. Zaragoza: Institución "Fernando el Católico", pp. 157-222.

Romano, J. (1928). "Hablando con Vilches" en Nuevo Mundo, 16 de marzo de 1928, p. 17.

SÁNCHEZ COLLANTES, S. (2017). “Republicanos y masones en los cafés: un estímulo para la sociabilidad disidente en la España contemporánea (1800-1931)" en DELGADO IDARRETA, J. M. y POZUELO ANDRÉS, Y. (coords.), La masonería hispano-lusa y americana de los absolutismos a las democracias (1815-2015). Zaragoza: Centro de Estudios Históricos de la Masonería Española, pp. 405-426.

VÁZQuez AstorgA, M. (2017). “La pintura decorativa y el café de San Millán de Madrid: la decoración de Manuel Zapata y Seta en 1891" en Artigrama. Universidad de Zaragoza, núm. 32, pp. 363-380.

Velasco ZaZO, A. (1934). “Estampas del pasado. El Madrid de Fornos” en La Época, 24 de setiembre de 1934, p. 3.

Velasco Zazo, A. (1945). El Madrid de Fornos. Retrato de una época. Madrid: Librería General de Victoriano Suárez.

Villacorta BAÑos, F. (1985). El Ateneo de Madrid (1885-1912). Madrid: Consejo Superior de Investigaciones Científicas. Centro de Estudios Históricos.

ZAMACOIS, E. (1935). "Tipos de café" en Ahora, 3 de diciembre de 1935, p. 18.

ZOZAYA MONTES, M. (2008). El Casino de Madrid: ocio, sociabilidad, identidad y representación social (Tesis Doctoral defendida el 28 de marzo de 2008 en el Departamento de Historia Contemporánea de la Universidad Complutense de Madrid, y en acceso abierto en: TDX). 